\title{
Comunicación
}

\section{AISLAMIENTO DE BACTERIAS Y HONGOS EN TEJIDOS DE PAICHE (Arapaima gigas) CRIADOS EN CAUTIVERIO}

\author{
Isolation of Bacteria and Fungi in Tissues of Paiche (Arapaima gigas) \\ REared in CaPTIVITY
}

\author{
Enrique Serrano-Martínez ${ }^{1,3}$, Verónica Castro P. ${ }^{1}$, Marco Quispe H. ${ }^{1}$, \\ Gina Casas V. ${ }^{1}$, Jorge León Q. ${ }^{2}$
}

\section{Resumen}

Se evaluó la presencia de agentes bacterianos y micóticos en 120 paiches (Arapaima gigas) de dos centros de cultivo de la Amazonía peruana. Se reporta la presencia de siete agentes bacterianos: Pseudomonas spp, Bacillus spp, Staphylococcus spp, Streptococcus spp, Escherichia spp, Aeromonas hydrophila y Corynebacterium spp, y de un hongo: Saprolegnia spp.

Palabras clave: Arapaima, granja piscícola, cultivo, bacterias, hongos, Amazonía peruana

\section{Abstract}

This study evaluated the presence of bacterial and micotic agents in 120 paiches (Arapaima gigas) in two fish farms in the Peruvian Amazon. Findings included seven bacterial agents: Pseudomonas spp, Bacillus spp, Staphylococcus spp, Streptococcus spp, Escherichia spp, Aeromonas hydrophila and Corynebacterium spp, and one fungus: Saprolegnia spp.

Key words: Arapaima, fish farm, culture, bacteria, fungi, Peruvian Amazon

${ }^{1}$ Grupo SALUVET-UPCH, Facultad de Veterinaria y Zootecnia, Universidad Peruana Cayetano Heredia, Lima

${ }^{2}$ Facultad de Ciencias Biológicas, Universidad Nacional Mayor de San Marcos, Lima

${ }^{3}$ E-mail: enrique.serrano@upch.pe

Recibido: 16 de mayo de 2012

Aceptado para publicación: 27 de agosto de 2013 


\section{INTRODUCCIÓN}

Arapaima gigas («paiche») es uno de los dos peces más grandes de América del Sur, pudiendo llegar a medir más de $2 \mathrm{~m}$ de longitud y pesar más de $100 \mathrm{~kg}$. En el Perú, el paiche es una especie de gran importancia para el poblador amazónico, por ser fuente de alimentación y generador de ingresos a través de la comercialización de sus productos (Salvo-Souza y Val, 1990). La sobrepesca de esta especie en su medio natural ha motivado que las autoridades locales y regionales estén promocionando su cultivo en ambientes controlados; sin embargo, el cultivo de esta y otras especies acuáticas predispone a la presentación de enfermedades debido a factores como calidad del agua, temperatura, alimentación y densidad animal por unidad de espejo de agua, entre otros (Penagos et al., 2009; Pacic, 2010).

En la mayoría de los casos, las enfermedades ocurren como resultado de una compleja interacción entre el patógeno, el pez y el estrés ambiental, incrementándose la susceptibilidad del hospedero a la enfermedad (Hedrick, 1998). En general, las enfermedades bacterianas en peces no se desarrollan simplemente como el resultado de una exposición al agente infeccioso, sino que son dependientes de situaciones de estrés causadas por el medioambiente o el manejo en su crianza (Ruangpan, 1988). Por otro lado, las micosis constituyen uno de los aspectos menos explorados de la ictiopatología pese a que producen grandes pérdidas económicas en acuicultura (Meyer, 1991). Las micosis no solo afectan la salud de los peces sino, además, afectan la calidad del producto destinado al consumidor (Kinkelin et al., 1985).

Los estudios en sanidad en el paiche son escasos. Se dispone de los trabajos realizados por Kodama et al. (1987) y Choresca et al. (2008) que reportan la presencia de Salmonella arizonae y Serratia fonticola, respectivamente. En Perú, Rebaza et al. (2007) reportaron la presencia de Pseudo- monas spp, Bacilllus spp, Escherichia spp, Enterobacter spp y Klebsiella spp en paiches de cultivo, siendo necesario obtener mayor información sobre la variabilidad microbiana en diferentes estadios de desarrollo, a fin de poder elaborar programas de manejo sanitario para mejorar los niveles productivos en esta especie. Por ello, el objetivo del presente estudio fue determinar la presencia de bacterias y hongos en paiches procedentes de granjas piscícolas y sin signos infecciosos evidentes.

\section{Materiales y Métodos}

El estudio se llevó a cabo con paiches de dos centros de cultivo localizados en la Carretera Iquitos-Nauta, provincia de Maynas, Región Loreto, quienes reportaban 1 a $2 \%$ de mortalidad por causas no diagnosticadas. Se trabajó con 120 paiches criados sin signos clínicos de enfermedad, que fueron divididos en cuatro grupos etarios (10-30, 31-180, 181-365 y >365 días de edad) de 30 animales cada uno.

Los paiches fueron transportados vivos al Laboratorio de Microbiología de la Universidad Nacional de la Amazonía Peruana entre mayo de 2009 y enero de 2011. Se re colectaron muestras de hígado, riñón, branquias y líquido peritoneal para la detección de bacterias, y piel para analizar la presencia de hongos. Las muestras para determinaciones bacteriológicas fueron inoculadas en caldo de cultivo tripticasa soya (TSB) e Infusión Cerebro Corazón (BHI); posteriormentesesembraron en placas en agar tripticasa soya (TSA) y agar sangrey se incubaron a 28 ${ }^{\circ} \mathrm{C}$ por 24 horas. Asimismo, el aislamiento de hongos se realizó mediante cultivo en agar Sabouraud dextrosa con antibiótico (penicilina). Todas las muestras, en sus respectivos medios de cultivo, fueron trasladadas en una caja isotérmica a $27^{\circ} \mathrm{C}$ al Laboratorio de $\mathrm{Mi}$ crobiología y Parasitología de la Universidad Peruana Cayetano Heredia (UPCH) en Lima. El transporte tomó tres horas. 
Cuadro 1. Prevalencia de agentes bacterianos en órganos internos y micóticos en piel de paiches (Arapaima gigas) procedentes de dos centros de cultivo de la provincia de Maynas, Loreto, Perú, según grupo etario (30 peces por grupo)

\begin{tabular}{ccccc}
\hline \multirow{2}{*}{$\begin{array}{c}\text { Edad } \\
(\text { días })\end{array}$} & \multicolumn{2}{c}{ Agentes bacterianos } & \multicolumn{2}{c}{ Agentes micóticos } \\
\cline { 2 - 5 } & $\begin{array}{c}\text { Positivos } \\
(\mathrm{n})\end{array}$ & $\begin{array}{c}\text { Prevalencia }^{1} \\
(\%)\end{array}$ & $\begin{array}{c}\text { Positivos } \\
(\mathrm{n})\end{array}$ & $\begin{array}{c}\text { Prevalencia } \\
(\%)\end{array}$ \\
\hline $10-30$ & 13 & $43.3 \pm 17.7$ & 0 & 0 \\
$31-180$ & 6 & $20.0 \pm 14.3$ & 3 & $10.0 \pm 10.7$ \\
$181-365$ & 9 & $30.0 \pm 16.4$ & 6 & $20.0 \pm 14.3$ \\
$>365$ & 16 & $53.3 \pm 17.9$ & 4 & $13.3 \pm 12.2$ \\
\hline
\end{tabular}

${ }^{1}$ Prevalencia \pm intervalo de confianza

En la UPCH, las colonias fueron recogidas en tubos con medio TSA glicerinado, conservándose a temperatura ambiente hasta su identificación. Por otro lado, las muestras de piel se siguieron incubando bajo las mismas condiciones por 15 días, y posteriormente se sembraron en placas de Agar Patata Dextrosa y Agar Harina de Maíz («Corn Meal Agar») bajo las mismas condiciones, observándose en forma diaria hasta su identificación.

Los aislamientos bacterianos fueron sometidos a pruebas convencionales de identificación según metodologías descritas en el Manual of Systematic Bacteriology (Koneman et al., 2008), complementadas con pruebas bioquímicas señaladas para bacterias de importancia médica (McFaddin, 1997).

Se calcularon las frecuencias de prevalencia y el intervalo de confianza (Armitage et al., 2008), con un nivel de confianza del $95 \%$.

\section{Resultados y Discusión}

El presente estudio, realizado en 120 paiches de diversos estadios de desarrollo y procedentes de centros de cultivo de la Provincia de Maynas, Región Loreto, demostró la presencia de agentes bacterianos en órganos internos y de agentes micóticos en piel en el 36.7 y $10.8 \%$ de los peces, respectivamente (Cuadro 1).

Se aislaron bacterias de los géneros Pseudomonas, Bacillus, Escherichia, Aeromonas, Corynebacterium, Staphylococcus y Streptococcus, siendo estas dos últimas las de mayor prevalencia (Cuadro 2). Los resultados son similares a los hallados por Rebaza et al. (2007) quienes reportaron la presencia de bacterias en alevinos y juveniles de paiches criados en cautiverio en la región amazónica del Perú.

La distribución numérica por grupo etario se muestra en el Cuadro 3. Todos los grupos mostraron la presencia de algún agente bacteriano. 
Cuadro 2. Prevalencia y tejido afectado por agentes bacterianos y micóticos en 120 paiches (Arapaima gigas) procedentes de dos centros de cultivo de la provincia de Maynas, Loreto, Perú

\begin{tabular}{|c|c|c|c|}
\hline Microorganismos & $\begin{array}{c}\text { Muestras } \\
\text { positivas } \\
\text { (n) }\end{array}$ & $\begin{array}{c}\text { Prevalencia } \pm \\
\text { I.C. }{ }^{1} \\
(\%)\end{array}$ & Tejido o fluido corporal \\
\hline \multicolumn{4}{|l|}{ Bacterias } \\
\hline Pseudomonas spp & 7 & $5.8 \pm 4.2$ & $\begin{array}{l}\text { Hígado, branquias y líquido } \\
\text { peritoneal }\end{array}$ \\
\hline Bacillus spp & 7 & $5.8 \pm 4.2$ & $\begin{array}{l}\text { Branquias y líquido } \\
\text { peritoneal }\end{array}$ \\
\hline Staphylococcus spp & 18 & $15.0 \pm 6.4$ & $\begin{array}{l}\text { Hígado, líquido peritoneal y } \\
\text { riñón }\end{array}$ \\
\hline Streptococcus spp & 20 & $16.7 \pm 6.7$ & $\begin{array}{l}\text { Hígado, líquido peritoneal y } \\
\text { riñón }\end{array}$ \\
\hline Escherichia spp & 2 & $1.7 \pm 2.3$ & Hígado y líquido peritoneal \\
\hline Aeromonas hydrophila & 2 & $1.7 \pm 2.3$ & Riñón \\
\hline Corynebacterium spp & 3 & $2.5 \pm 2.8$ & Líquido peritoneal \\
\hline \multicolumn{4}{|l|}{ Hongos } \\
\hline Saprolegnia spp & 13 & $10.83 \pm 5.6$ & Piel \\
\hline
\end{tabular}

${ }^{1}$ Intervalo de confianza del $95 \%$

Cuadro 3. Número de ocurrencias de aislamiento de bacterias y hongos hallados en tejidos y fluidos corporales de 120 paiches (Arapaima gigas), procedentes de dos centros de cultivo de la provincia de Maynas, Loreto, Perú, según grupo etario $(\mathrm{n}=30$ por grupo)

\begin{tabular}{lcccc}
\hline & \multicolumn{5}{c}{ Días de edad } \\
\cline { 2 - 5 } & $10-30$ & $31-180$ & $181-365$ & $>365$ \\
\hline Bacterias & 2 & 2 & 1 & 2 \\
Pseudomonas spp & 5 & 2 & 0 & 0 \\
Bacillus spp & 6 & 0 & 4 & 8 \\
Staphylococcus spp & 3 & 0 & 6 & 11 \\
Streptococcus spp & 0 & 2 & 0 & 0 \\
Escherichia spp & 0 & 0 & 1 & 1 \\
Aeromonas hydrophila & 0 & 0 & 1 & 2 \\
Corynebacterium spp & & & & 4 \\
Hongos & 0 & 3 & 6 & \\
$\quad$ Saprolegnia & & & & \\
\hline
\end{tabular}


Se demostró la presencia de Saprolegnia spp en piel en 13 ejemplares, y en seis de ellos en forma concomitante con agentes bacterianos como Pseudomonas, Aeromonas hydrophila, Staphylococcus y Streptococcus, los cuales estuvieron presentes en hígado, riñón y líquido peritoneal. Los hongos son organismos saprofitos ubicuos que se encuentran normalmente en ecosistemas donde abunda la materia orgánica en descomposición. Ocasionalmente, bajo situaciones estresantes (cambios bruscos de $\mathrm{pH}$, temperatura, etc.) producen inmunosupresión que puede derivar en diversas patologías (Bruno y Stamps, 1987; Durán et al., 1987), por lo que son considerados como patógenos secundarios a enfermedades bacterianas y virales (Wolke, 1975; Richard, 1977) o como consecuencia de traumatismos y posterior formación de heridas y úlceras (Roberts y Shepherd, 1974).

Saprolegnia spp tuvo una mayor presencia en individuos mayores de seis meses (Cuadro 3), lo cual podría estar relacionado a las condiciones de manejo del paiche, ya que generalmente en los centros de cultivo de la Amazonía peruana, aquellos menores de 30 días de edad son colocados en artesas de madera ocasionado una deficiente aireación o circulación de oxígeno, y por lo tanto, afectando las condiciones adecuadas para el desarrollo del hongo (Liu y Volz, 1976; González de Canales et al., 2001).

La presencia de microorganismos detectados en el paiche no necesariamente indica que sean causantes directos de alguna patología específica; sin embargo, la literatura revisada señala la frecuencia de estos microorganismos bacterianos como patógenos ocasionales en muchos organismos acuícolas (Rebaza et al., 2007).

\section{Conclusiones}

Se reporta la presencia de siete agentes bacterianos (Pseudomonas, Bacillus, Staphylococcus, Streptococcus, Escherichia,
Aeromona hydrophilas y Corynebacterium) y un agente micótico (Saprolegnia) en paiches de cultivo de la Amazonía peruana.

\section{Agradecimientos}

Los autores agradecen a los acuicultores Sres. Wenseslao Solsol y Manuel García por el apoyo brindado en campo, al MSc Guillermo Leguía por su asesoría profesional y a los biólogos César Correa y Debbie Reátegui de la Dirección Regional de la Producción (DIREPRO), Loreto, por el apoyo y prestación de las instalaciones. Asimismo, a la Universidad Nacional de la Amazonía Peruana (UNAP) por el uso del laboratorio. Un especial agradecimiento al Blgo. Carlos Cabrera por su incondicional apoyo como profesional y amigo, y que Dios lo guarde en su gloria. El presente trabajo fue desarrollado mediante el apoyo financiero de la Presidencia del Consejo de Ministros a través del FINCyT (Contrato N. ${ }^{\circ}$ 017-FINCyT-PIBAP2009).

\section{Literatura Citada}

1. Armitage P, Berry G Matthews JNS. 2008. Statistical methods in medical research. $4^{\text {th }}$ ed. Oxford, UK: Blackwell Science. 832 p.

2. Bruno DW, Stamps DJ. 1987. Saprolegniasis of Atlantic salmon, Salmo salar L., fry. J Fish Dis 10: 513-517.

3. Choresca CH, Kim JH, Gomez DK, Jang H, Joh SJ, Park SC. 2008. Isolation of Serratia fonticola from pirarucu Arapaima gigas. Korean J Vet Res 48(1): 89-92.

4. Durán A, Rodríguez-Aparicio LB, Reglero A, Pérez-Díaz J. 1987. Changes in serum enzymes of Saprolegnia-infected brown trout, Salmo trutta L. J Fish Dis 10: 505-507.

5. González de Canales ML, Bosco J, González del Valle MA, Sarasquete C. 2001. Saprolegniasis en poblaciones naturales de peces. Ciencias Marinas 27(1): 125-137. 
6. Hedrick RP. 1998. Relationships of the host, pathogen, and environment: implications for diseases of cultured and wild fish populations. J Aquat Anim Health 10: 107-111.

7. Kinkelin P, Michel CH, Ghittino P. 1985. Hongos y micosis. En: Tratado de las enfermedades de los peces. España: Ed Acribia. p 109-116.

8. Kodama H, Nakanishi Y, Yamamoto F, Mikami T, Izawa H, Imagawa T, et al. 1987. Salmonella arizonae isolated from a pirarucu, Arapaima gigas Cuvier, with septicaemia. J Dish Dis 10: 509-512.

9. Koneman E, Winn W, Allen A, Janda W, Procop G, Scherenckenberger P, Wood G 2008. Diagnóstico microbiológico: texto y atlas en color. $6^{\circ}$ ed. Buenos Aires: Médica Panamericana. 1475 p.

10. Liu C, Volz PA. 1976. On the ecology of Sapr-legniaceae. Phytologica 34: 209230.

11. McFaddin JF. 2003. Pruebas bioquímicas para la identificación de bacterias de importancia clínica. $3^{\circ}$ ed. España: Médica Panamericana. $850 \mathrm{p}$.

12. Meyer FP. 1991. Aquaculture disease and health management. J Anim Sci 69: 42014208.
13. Pacic A. 2010. Cría de pacú en cautiverio. Argentina: INTA Centro Regional Chaco Formosa. $11 \mathrm{p}$.

14. Penagos G, Barato P, Iregui C. 2009. Sistema inmune y vacunación de peces. Acta Biol Colomb 14(1): 509-512.

15. Rebaza C, Padilla P, Mortero V. 2007. Identificación de bacterias patógenas, hongos y parásitos en alevinos y juveniles de paiche manejados en ambientes controlados. En: Memoria Institucional 2007. Programa de Investigación en Ecosistemas Acuáticos del IIAP.

16. Richard RH. 1977. Mycology of fishes. In: Roberts RJ (ed). Fish pathology. London: Bailiere Tindall. p 456-498.

17. Roberts RJ, Sheperd CJ. 1974. Handbook of trout and salmon diseases. London: Fishing News Books. 168 p.

18. Ruangpan L. 1988. Diseases of cultured seabass, Lates calcarifer. In: Seabass (Lates calcarifer) culture in Thailand. FAO. [Internet]. Available in: http://www.fao.org/docrep/field/003/ AB707E/AB707E00.htm

19. Salvo-Souza RH, Val AL. 1990. O gigante das águas doces. Ciên Hoje 11: 9-12.

20. Wolke RE. 1975. Pathology of bacterial and fungal disease affecting fish. In: The pathology of fishes. Wisconsin, USA: University of Wisconsin Press. p 33-116. 